\title{
Air Flow Door Barrier for Airborne Infection Isolation Rooms
}

\author{
Bård Venås ${ }^{1}$, Anders Welde Vikan ${ }^{1}$, Merethe Cecilie Lind ${ }^{1}$, Trond Thorgeir Harsem ${ }^{1,2,{ }^{*}}$ \\ ${ }^{1}$ Norconsult AS, Sandvika, Norway \\ ${ }^{2}$ Oslo Metropolitan University, Norway
}

\begin{abstract}
Airborne Infection Isolation Rooms (AIIRs) are used in hospitals to counter the spread of airborne infections. These rooms usually work well as long as the doors to the patient rooms are closed. However, passage through open doorways initiates air flows that may lead to containment failure. This paper presents a new "Air Flow Door Barrier" system for AIIRs and analyses its efficiency through CFD simulations. The overset mesh method is used to represent a hinged door and a person transiting from the patient room to the anteroom. The new system consists of a fan which introduces filtered patient room air into the anteroom through large displacement diffusors. It runs in synchronization with the door operator and produces an evenly distributed velocity across the open doorway. It is found that the system has the potential to remove nearly all transfer of air out from the patient room. The development of the system is part of an ongoing project aimed at finding cost-effective solutions for retrofitting existing patient rooms. However, the system also has the potential to be beneficial when considering inclusion in new standard AIIRs.
\end{abstract}

\section{Introduction}

Airborne infection isolation rooms (AIIRs) are used in hospitals to counter the spread of airborne infections. These rooms are built with tight room envelopes and are equipped with ventilation systems keeping them at lower air pressure than the surrounding parts of the building. The under-pressure ensures that flow through remaining openings is directed into the patient room, inhibiting possibly contaminated air from escaping the patient room.

If properly built such systems work well as long as the door to the AIIR is closed. However, once the door is opened the pressure differential is instantaneously neutralised and air is free to flow through the doorway in both directions. In addition to the removal of the barrier, the movement of the door and persons passing through the doorway initiates air flows that cause exchange of air between the two rooms. Previous studies have shown that door opening, and passage, are significant causes for containment failure in hospitals [1, 2].

To reduce contamination from this type of "passage induced" air exchange AIIRs usually have an anteroom between the patient room and the hospital corridors outside. This anteroom has a high number of air changes per hour $(\mathrm{ACH})$ to dilute the "passage induced" air that is transferred from the patient room. Even with high $\mathrm{ACH}$, the necessary holding time for personnel in the anteroom to assure a full purge or dilution of air from the patient room is substantial.

The work presented in this paper stems from an ongoing research project aimed at developing new costeffective solutions for AIIRs, in order to increase the availability of such facilities in the case of large-scale pandemics. Previous publications from the project have described air leakage/exchange for AIIRs through both CFD-simulations and laboratory experiments [3, 4]. These detailed analyses spurred the idea of limiting this air transfer by designing a new type of separate "standalone" and "add-on" ventilation system. In other words, a system that can be retrofitted to existing normal patient rooms. However, the system is not limited to this but could also be included as part of any new standard AIIR, and in other rooms where air exchanges between clean and less clean areas should be avoided.

The system will start in synchronisation with the movement of the door using the same signals as the door operator. Its main function is to provide a unidirectional air flow through the door - from the anteroom to the patient room when the door is open. The system is schematically shown in Figure 1. As the opening area is large (the door is $\sim 2.5 \mathrm{~m}^{2}$ ) the flow cannot be set up simply by establishing a pressure differential between the rooms, as is the case for closed doors. The air flow velocity through the open door is of importance. If the velocity flow through the door is too high, it can set up a counter flow in the other direction that increases the air exchange. It is thus necessary to carefully control the flow in the rooms to prevent mixing of air through the door opening. To assure well distributed and low velocity diffuse air flow through the door opening it was chosen to employ large displacement diffusers. For this first evaluation two large 90-deg corner diffusers (620 $\mathrm{mm}$ radius) were placed in the anteroom along the wall to the corridor. The necessary dimensions of the diffusers will be investigated in future work.

* Corresponding author: T.Thorgeir.Harsem@norconsult.com 


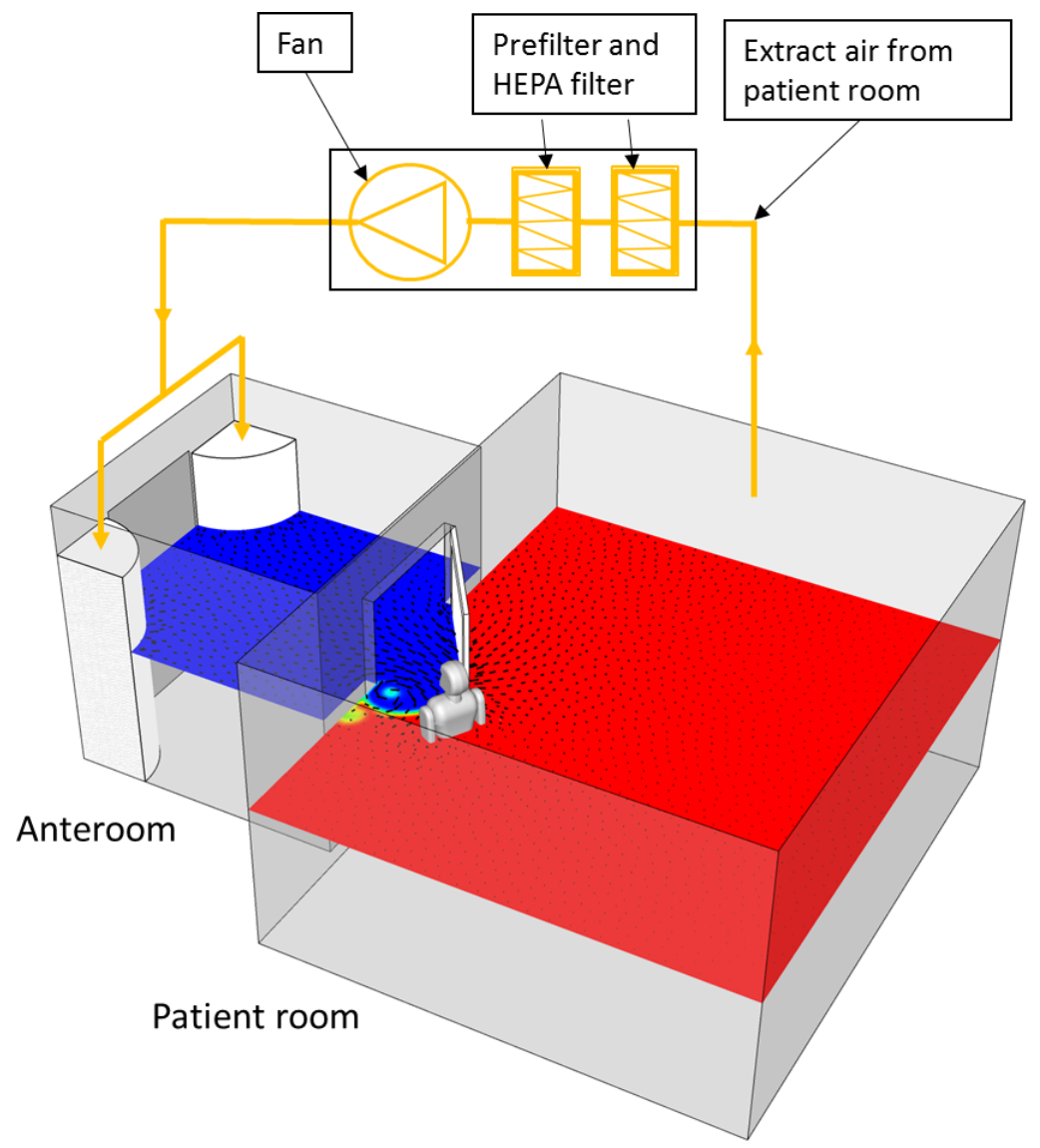

Fig. 1. Principle for the Air Flow Door Barrier.

To provide the necessary high flow rates without expensive additions to the normal ventilation, the system uses recirculated air from the patient room. Since airborne infections is caused by bacteria and viruses travelling on dust particles or aerosolized respiratory droplets, the air is filtrated through a pre-filter and a High Efficiency Particulate Air (HEPA) filter before it is reintroduced to the anteroom through the corner diffusors. A HEPA filter is nearly $100 \%$ efficient in removing particles of all sizes [5].

\section{Methodology}

The main goal of the simulations was to analyse the flows induced by the movement of a hinged door and by the person passing through the doorway (i.e. in addition to the ventilation flows). To achieve this the "Overset mesh method" available within the framework of the commercial CFD code ANSYS Fluent was used. The background for the choice of simulation method has been detailed in a previous paper where it is argued that this method is the most flexible and accurate way currently available for such simulations [4].

In the overset mesh approach the temporally changing geometry is modelled using separate meshes for the "background" (rooms) and for each moving object (door and person). The meshes are combined by the code using special handling in the regions where they overlap. As an example, Figure 2 shows the resulting mesh structure at one specific time during the passage. The extent of the original overset meshes is marked with solid lines in the figure, whereas the coloured cells show the cells that are currently active in the simulation.

A real person walks in a very complicated manner, moving the body and limbs in a coordinated way. Although such movement is possible to mimic with the Overset Mesh method (using one mesh for each body part) - it was chosen to implement a simpler "sliding" representation of the person at this time. The model of the person, and the Overset Mesh surrounding it, is illustrated in Figure 3. The lay-out of the rooms, the existing ventilation system, and simulations results for passages have been reported in Harsem et al $[3,4]$. For a full description of geometry, diffusors, and heat sources in the rooms etc. see these references. In the CFD model, these parameters where kept as close as possible to the parameters in the laboratory experiments for the reference case with which the results are compared [3].

The timing and movement of door and person was tried to be kept as close as possible to a realistic passage for an actual person (not a dummy mannequin). Table 1 and Figure 4 presents the timing and waypoints for the passage. In the previous paper $[3,4]$ both entering and exiting the patient room was investigated. In the testing of the new air barrier system presented in this paper only "exiting" is included. This was as the air barrier system is likely to be more effective when the person moves in the direction of the barrier air flow through the doorway. 


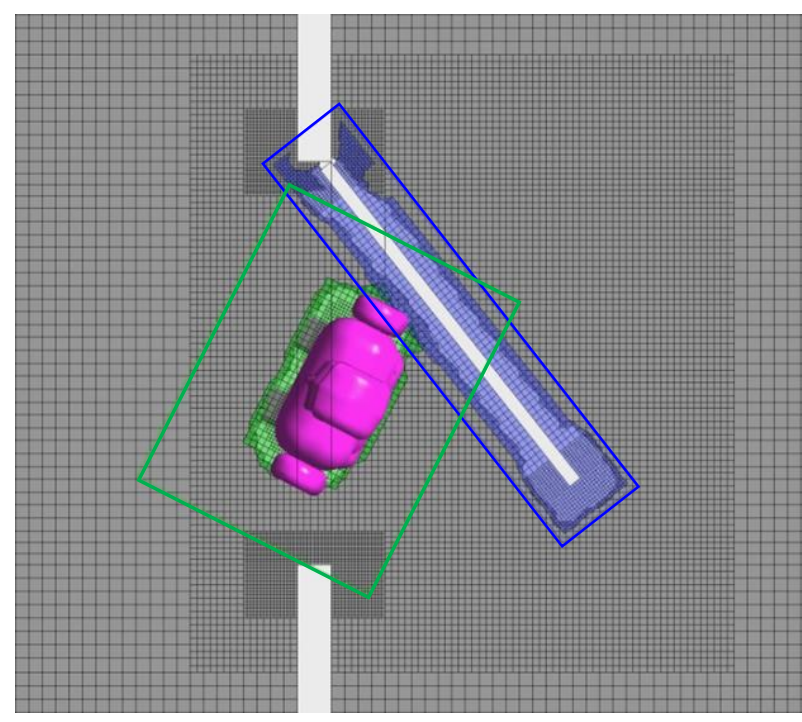

Fig. 2. Active cells for background mesh (grey), door mesh (blue), and person (green), during passage through the door.

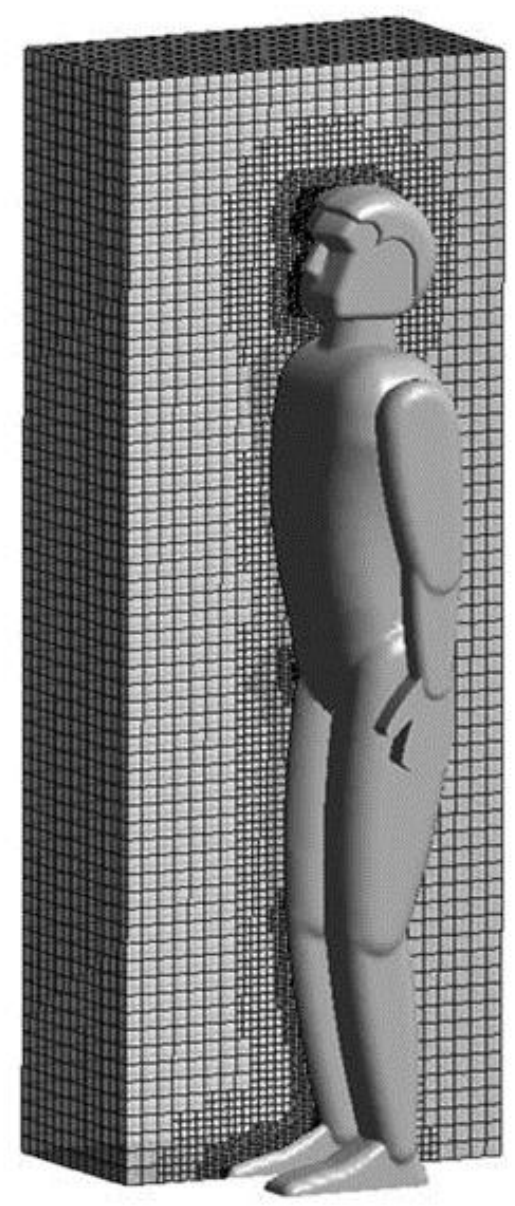

Fig. 3. Model of mesh for moving person.

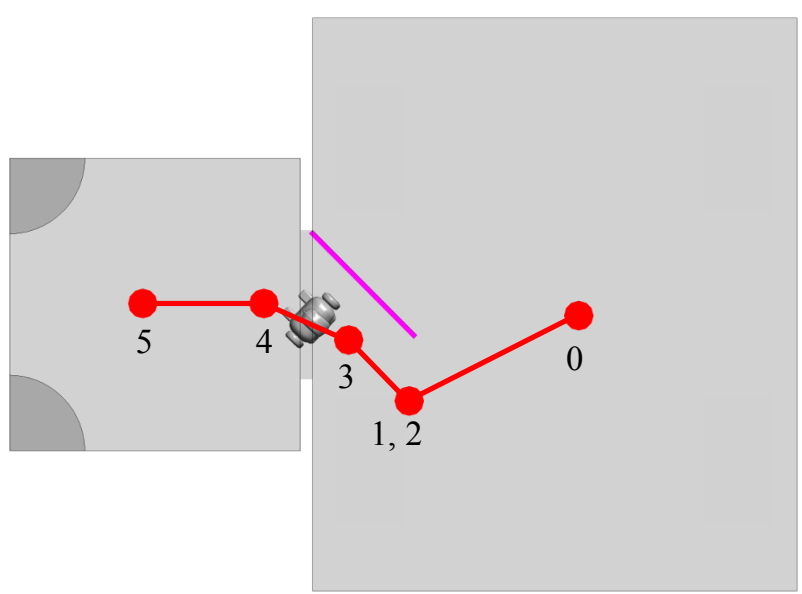

Fig. 4. Waypoints for the movement exiting the patient room into the anteroom

Table 1. Waypoints describing the person and door when moving from patient room to anteroom.

\begin{tabular}{|c|c|c|}
\hline $\begin{array}{l}\text { Waypoint } \\
\text { no. }\end{array}$ & Time & Action \\
\hline$\bullet 0$ & $0 \mathrm{~s}$ & $\begin{array}{l}\text { Person starts to walk from } \\
\text { centre of patient room. }\end{array}$ \\
\hline - 1 & $2.4 \mathrm{~s}$ & $\begin{array}{l}\text { Person stops, pushes } \\
\text { operator, door starts to open, } \\
\text { and air flow barrier starts }\end{array}$ \\
\hline - 2 & $3.9 \mathrm{~s}$ & Person starts walking again. \\
\hline- & $4.4 \mathrm{~s}$ & Door stops in open position. \\
\hline - 3 & $4.8 \mathrm{~s}$ & Change of walking direction. \\
\hline - 4 & $5.3 \mathrm{~s}$ & Change of walking direction. \\
\hline- & $5.4 \mathrm{~s}$ & Door starts to close. \\
\hline$\bullet 5$ & $6.7 \mathrm{~s}$ & Person stops in anteroom. \\
\hline- & $9.4 \mathrm{~s}$ & $\begin{array}{l}\text { Door closes, and } \\
\text { air flow barrier stops. }\end{array}$ \\
\hline
\end{tabular}



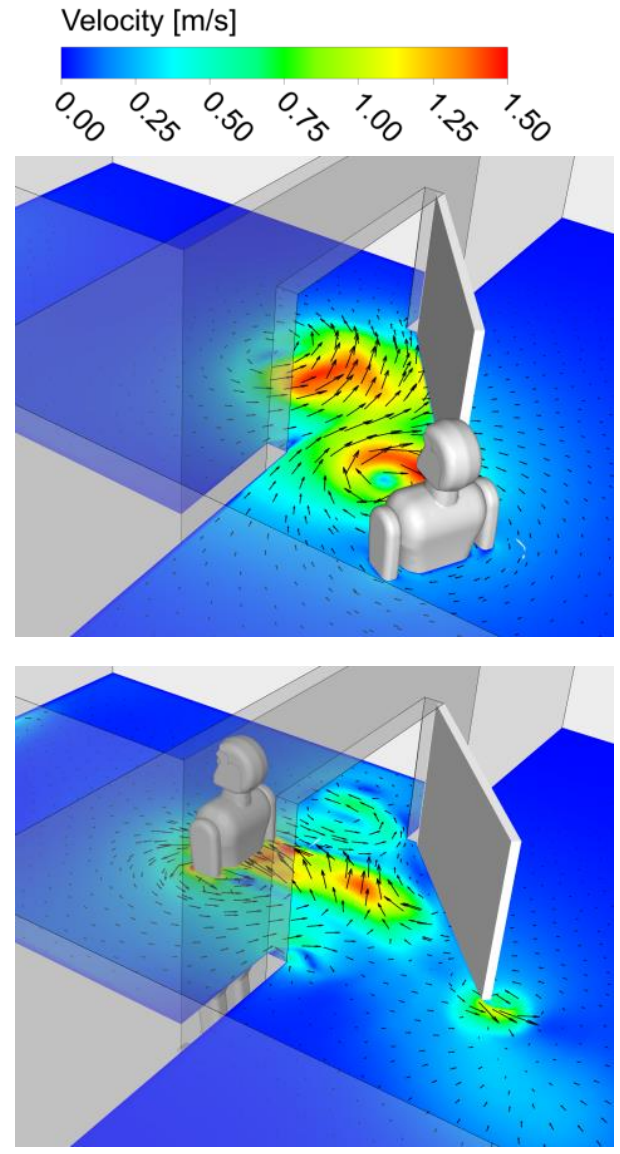

Fig. 5. Velocity induced by movement of door (top) and movement of person (bottom).

\section{Contamination in the reference case}

The methods and results from the reference case, i.e. air exchange in a normal patient room with no air flow barrier are presented in two previous publications [3, 4]. It was found that the average air transfer due to door opening and passage was $781 \mathrm{~L}$ in the CFD simulations and $729 \mathrm{~L}$ in the corresponding laboratory experiments.

A bit simplistically, one may describe the physics of the contamination failure during passage as two separate phenomena. These two being, respectively, air exchange caused by the movement of the door, and by the persons moving through the doorway.

The first phenomenon, "door induced air flow", can be described as follows. When a hinged door separating two rooms starts to open the air pressure increases in the room the door rotates towards and decreases in the room it rotates away from. This pressure difference initially induces a jet flow through the gradually opening gaps between the door and the door frame. As the door opens further the difference in pressure in the two rooms is neutralised, but the door movement continuously displaces air from the advancing side of the door towards the retreating side. In combination, the initial jet and the door movement, sets up the flow structures which can be seen as two counterrotating vortices in the top part of Figure 5. The resulting transfer of air between the two sides as is seen in the top part of Figure 3. These figures
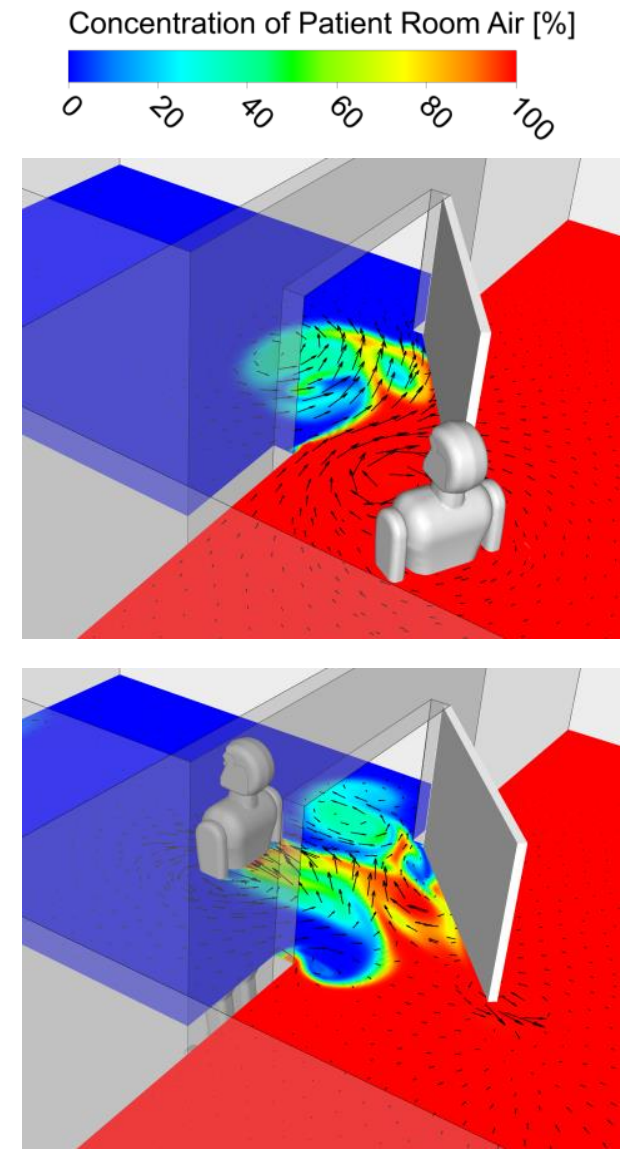

Fig. 6. Leakage of air from patient room to anteroom induced by movement of door (top) and movement of person (bottom).

are snapshots taken while the door still moves but before the person starts to move $(\mathrm{t}=3.8 \mathrm{~s})$.

The second phenomenon, "person induced air flow", is caused by air from the patient room being "trapped" in the wake behind the person, following him/her into the anteroom. The flow pattern and the transfer of patient room air can be seen in the bottom parts of Figure 5 and 6 . These figures are snapshots taken as the person moves further into the anteroom, and just after the door has started to close $(\mathrm{t}=5.8 \mathrm{~s})$.

It should be mentioned that this is a simplified description developed in order to facilitate discussions of the air flow barrier system in the following analysis. In reality the door and person induced flows are both highly three-dimensional, transient, and interlinked. 


\section{Results}

In the following CFD simulations of the reference case (Figure 7a) are compared to simulations with the air flow barrier system (Figure 7b-d). The results are shown for a horizontal plane $1.3 \mathrm{~m}$ above the floor, i.e. at chest height of the person. The pictures are taken at the same instant, but with different air flow rates. In the simulations with the air flow barrier three different flow rates were tested. These were respectively $\mathrm{Q}_{\text {barrier }}=300$, 500 and $1000 \mathrm{~L} / \mathrm{s}$. These flow rates correspond to average velocities of $0.12,0.2$, and $0.4 \mathrm{~m} / \mathrm{s}$ through the open area of the doorway.

In Figure $7 \mathrm{a}$ one can see the situation without the air flow barrier (corresponds to the top of Figure 3 but seen directly from above). The picture below shows that the intrusion of patient room air into the anteroom seems all but completely supressed by an air flow barrier rate of just $300 \mathrm{~L} / \mathrm{s}$ (Figure $7 \mathrm{~b}$ ). The air movement around the person, from the advancing to the retreating side of the door, remains relatively unchanged although slightly reduced in strength. The same is the case for the vortex in front of the person waiting for the door to open.

When increasing the barrier flow to $500 \mathrm{~L} / \mathrm{s}$ (Figure $7 \mathrm{c})$, the flow into the room increases and the door edge vortex is moved towards the person and the free edge of the door.

Increasing the flow further to $1000 \mathrm{~L} / \mathrm{s}$ (Figure 7d) moves the vortex away from the front of the person and sets up a continuous flow towards him/her. A small vortex exists behind the edge of the doorframe where the flow separates.

Table 2. Air transfer during passage.

\begin{tabular}{|c|c|c|}
\hline Flow in diffusors & Air transfer & $\begin{array}{c}\text { Air Transfer } \\
\text { (relative) }\end{array}$ \\
\hline $0 \mathrm{~L} / \mathrm{s}$ & $781 \mathrm{~L}$ & $100 \%$ \\
\hline $300 \mathrm{~L} / \mathrm{s}$ & $223 \mathrm{~L}$ & $29 \%$ \\
\hline $500 \mathrm{~L} / \mathrm{s}$ & $106 \mathrm{~L}$ & $14 \%$ \\
\hline $1000 \mathrm{~L} / \mathrm{s}$ & $29 \mathrm{~L}$ & $4 \%$ \\
\hline
\end{tabular}
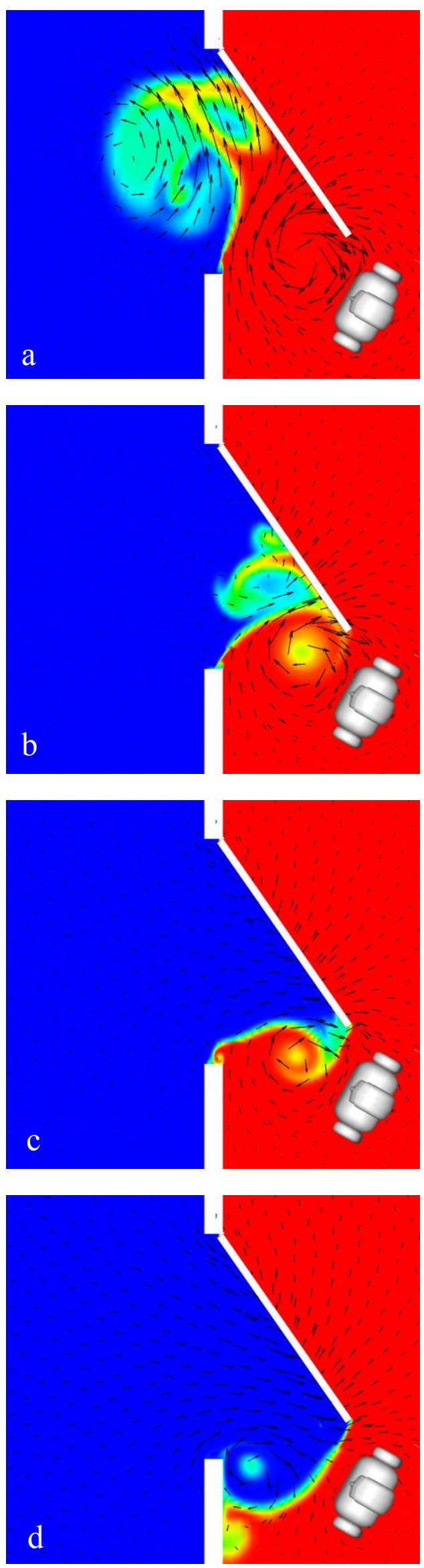

Fig. 7. Snapshots of leakage and flow structure during opening of door. Top to bottom: Qbarrier $=0,300,500$, and $1000 \mathrm{~L} / \mathrm{s}$. 
Figure 8a-d shows the situation as the person has moved through the door and is continuing into the anteroom. The flow pattern and concentrations seen in Figure 8a (reference case) are consequences of both door- and person-induced air flows. In Figure $8 \mathrm{~b}$ the air flow barrier is turned on at its lowest value, $300 \mathrm{~L} / \mathrm{s}$. The results indicate that the door-induced air transfer to the anteroom is effectively removed, but that the personinduced wake transfer persists.

Increasing the barrier flow further to respectively $500 \mathrm{~L} / \mathrm{s}$ and $1000 \mathrm{~L} / \mathrm{s}$ (Figures $8 \mathrm{c}$ and $8 \mathrm{~d}$ ) the ventilation air from the anteroom to the patient room clearly supresses all leakage caused by the door movement. One can see that anteroom air has passed the edge of the door and reached into the patient room.

The concentration of patient room air in the wake behind the person decreases with increasing air flow rates. However, some air is transferred even for the highest barrier flow tested.

Table 2 lists the total transfer of air from the patient room to the anteroom during the 7 second door opening sequence. Without the barrier 781 litres of air is being transferred between the rooms. With a barrier flow of $300 \mathrm{~L} / \mathrm{s}$ this amount is reduced to less than one third (223 litres). Increasing the flow to 500 and $1000 \mathrm{~L} / \mathrm{s}$ the amount is reduced to respectively $14 \%$ and $4 \%$ (106 and 29 litres).

\section{Discussion}

The simulations show that it is possible to reduce contamination risk in both normal patient rooms and in AIIRs significantly by employing a system that supplies high air flow rates diffusely, from the anteroom to the patient room during door openings. The system is being tested in laboratory experiments and the results from these tests will be published at a later stage.

As is shown in Figure 1 the final system will use a filter and fan system which is separate from the normal ventilation system. The characteristics of the exact startup of this system and the synchronization with the door opening/operator will be investigated in the next phase of the CFD simulations. In the present simulations a very rapid (0.2 second) ramp-up of the barrier flow was employed. Future work will include analysis of the system using realistic fan curves and pressure losses in filters. In addition, effects of the control system and the synchronization with the door opening will be tested. It is for instance possible that the actual system may require a slower start-up and that this for instance should be compensated by a slower start-up of the door movement.

The simulations indicate that it should be possible to remove the door-induced air transfer completely. The person-induced (wake) transfer however is reduced but not completely removed. The amount of transferred air decays with increasing barrier air flow as the velocities and turbulence, and thus dilution of trapped air in the wake, scales with the air speed relative to the person
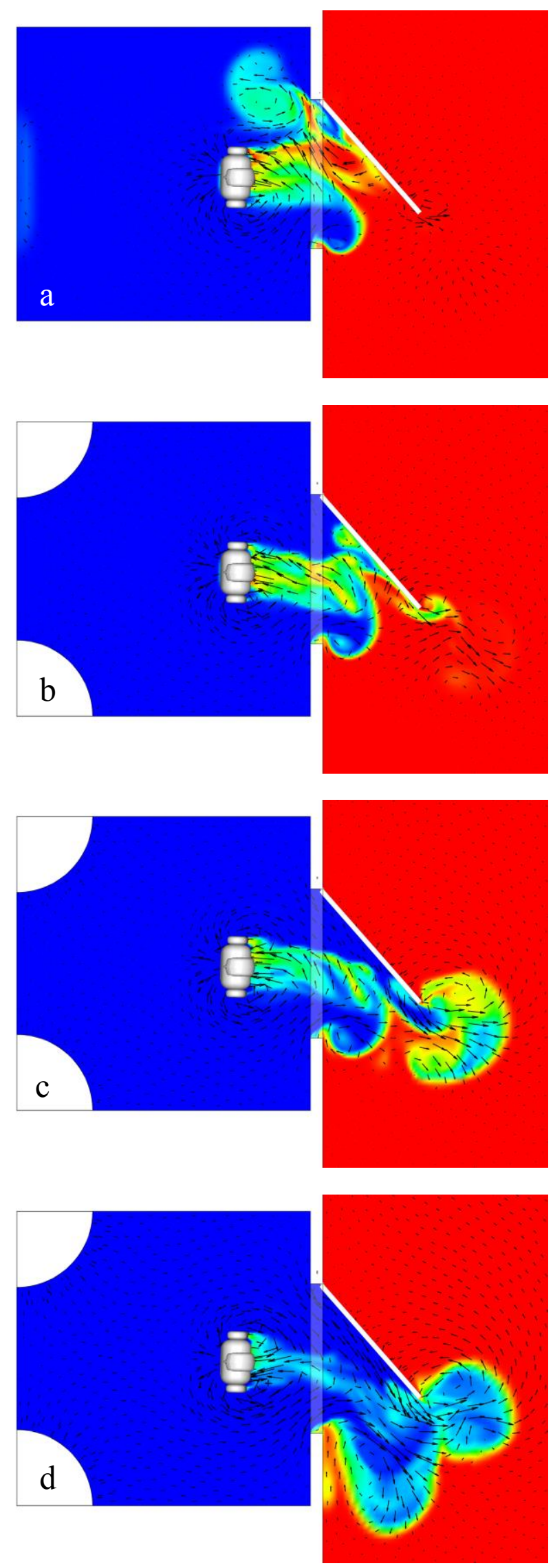

Fig. 8. Snapshots of leakage and flow structure caused by wake behind person. Top to bottom: $Q_{\text {air barrier }}=0,300,500$, and $1000 \mathrm{~L} / \mathrm{s}$. 
(walking speed + barrier flow air speed). The highest barrier flow, $1000 \mathrm{~L} / \mathrm{s}$, does not remove all transfer of air. As such, it is not likely that increasing the flow further is a realistic way to pursue even lower exchange rates. Possibilities for doing this however could include increasing the running time for the system (and opening time for the door) or procedural routines for the passage (how to move, stop etc.).

The size of the corner diffusers in the simulations corresponds to those chosen for the initial tests in the laboratory. To be on the safe side with respect to flow homogeneity these diffusers are large enough to deliver the maximum barrier air flow $(1000 \mathrm{~L} / \mathrm{s})$ within the limits in the product data sheets. That is to say, they satisfy the requirements for standard comfort ventilation with respect to noise, air flow velocities, and without excessive pressure loss. Strictly speaking this should not be necessary for the Air Flow Door Barrier system, which only runs during door openings. It should therefor be possible to use smaller diameter diffusers. This will be tested in physical prototypes.

Please note that this work has so far solely focused on hinged doors and not e.g. sliding doors. This choice has been due to that the overall project aims at upgrading existing normal patient rooms to "simplified AIIRs" and that most existing patient rooms have hinged doors (and that refurbishing these with sliding doors is difficult and expensive). Sliding doors have been shown in other studies to yield lower leakage rates than hinged doors during passage [6] and should be considered for new AIIRs. It is anyway considered likely that the system presented in this paper will be useful also for sliding doors.

\section{Conclusions}

This paper presents and investigates an idea for a system reducing the risk for contamination failure caused by door and person induced air flows. Such passages have been found to be a significant cause for containment failure in hospitals.

Simulations have been performed for three different door barrier air flows and is compared to the situation without the system. It is found that such a system can reduce the contamination failure in AIIRs significantly.

The work continues with laboratory experiments and development of prototypes, first by CFD simulations and then by validation of the designs in the laboratory, and finally in actual hospital environments.

\section{References}

1. P. Saarinen, P. Kalliomäki, H. Koskela, \& J. W. Tang. Large-eddy simulation of the containment failure in isolation rooms with a sliding door-An experimental and modelling study. In Building Simulation (Vol. 11, No. 3, pp. 585-596). Tsinghua University Press. (2018, June).
2. Kalliomäki, P., Saarinen, P., \& Koskela, H. Effect of Door Opening in Hospital Isolation Room. In 45th R 3 Nordic Symposium (p. 99).

3. T. T. Harsem, M. C. Lind, B Venås, P. Kalliomäki, H Koskela. Door and Passage Induced Air Exchange Across Hinged Door. Presented at the RoomVent and Ventilation 2018 Conference in Espoo, Finland (2018).

4. Harsem, T. T., Venås, B, Vikan, A. W., Lind, M. C., Kalliomäki, P., Koskela, H. CFD Simulations of Door and Passage Induced Air Exchange Across Hinged Door. Presented at the 39th AIVC conference "Smart ventilation for buildings" in September 2018 in Antibes Juan-Les-Pins, France. (2018).

5. W. J. Fisk. Health benefits of particle filtration. Indoor air, 23(5), 357-368 (2013).

6. P. Kalliomäki, P. Saarinen, J. W. Tang, and H, Koskela. Airflow patterns through single hinged and sliding doors in hospital isolation rooms. International Journal of Ventilation, 14(2), 111-126. (2015). 